formed that confidentiality on the part of the physician will be ensured. Sharing the information will occur only with other professionals who need to know. When appropriate, the physician should discuss the advisability of notifying a spouse or other sexual contacts. A woman who tests positively for the antibodies to the human immunodeficiency virus (HIV) should be advised that AIDS may be passed to any child she conceives.

It is necessary to stress the importance of being cautious of people who belong to organizations that offer "safe sex" simply because they issue a health card. Generally these health cards are out of date, and one has to question why such a person has a card like this in the first place. Tell your patients that if they have doubts about their sexual partner, they should use a condom. Additionally, patients should be informed not to practice anal intercourse, because the rectal mucosa bleeds readily, providing easy access for the virus to enter the body.

Given the background and considerations, I believe most physicians would agree AIDS is the most pressing public health problem in America today. This disease will affect each and every one of us. For those physicians who have not had an experience with this problem in their own practice, it is safe to suggest that they will, at least, be affected indirectly by the sheer economic impact of this crisis. If the public will heed and practice the above advice, I believe that the AIDS epidemic can be contained. If this advice is ignored, this disease will be with us for a very long time.

We must stop the spread of AIDS. The people of America need your full attention and dedication. The lives of people at risk, including unsuspecting young people and the unborn children, depend upon you.

C. EVERETT KOOP, M.D., SC.D.

Surgeon General

United States Public Health Service

\section{AIDS: A challenge for osteopathic physicians}

Information is abundant concerning the current and projected magnitude of this universal health threat called the acquired immune deficiency syndrome (AIDS). As each month passes, new concepts and facts become apparent requiring our constant attention, for it is a disease that will affect each of our lives and, for many, will alter the way we practice osteopathic medicine. The multiple psychosocial, legal, and ethical issues will demand our

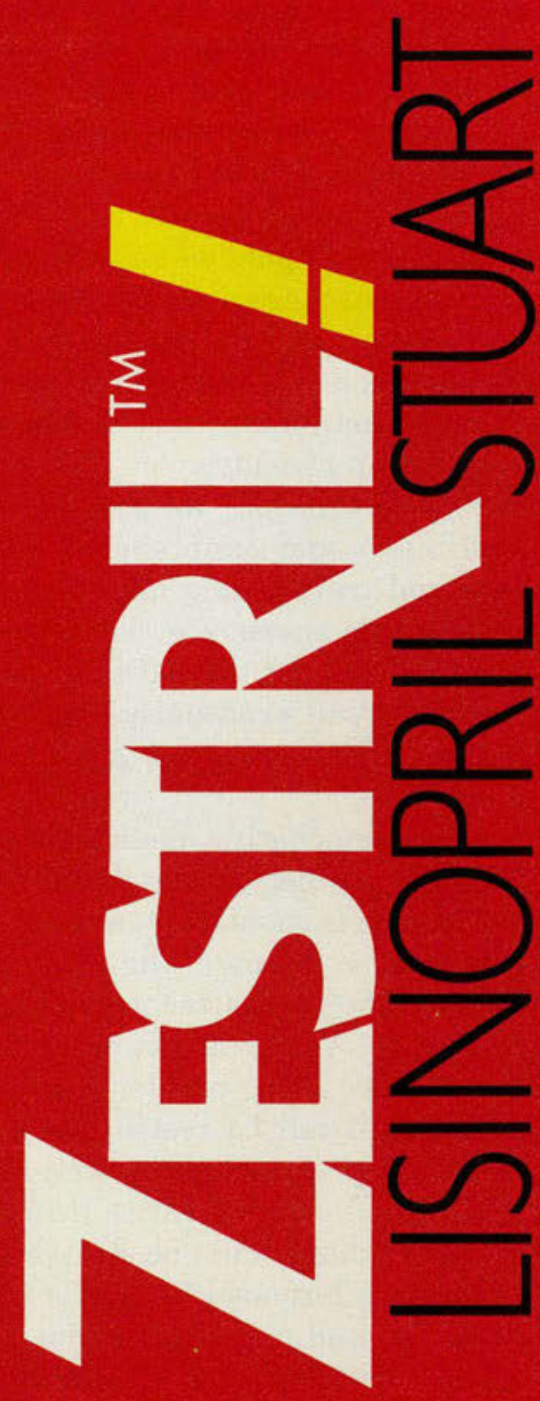


attention or, if for some inexplainable reason these issues don't impress some of us, the sheer economic impact will.

Infection with the human immunodeficiency virus (HIV) and AIDS will force medicine to become intensely involved in areas that have been neglected in the past. Our policies toward the terminally and chronically ill, the elderly and youth of our nation, and most certainly the indigent, will be restructured by the many issues surrounding this disease. We will soon be forced to define the value that society places on the quality of life. Restructuring of policies will take a collaborative effort of great magnitude between academia, the private sector, and the federal government. This effort demands careful thought now, for deficiencies do exist. Action must not be delayed anymore than it has been already.

As a profession, we provide our patients with continuous and comprehensive care, and we educate and train young men and women to become osteopathic physicians. Therefore, we must direct our plan against the AIDS crisis at two critical issues that will eventually lead to one goal-a profession better prepared to deal with this dreaded disease.

First, osteopathic medical education at the predoctoral, postdoctoral, and continuing medical education levels must be examined as it pertains to this disease. Many of the educational deficiencies that will be recognized are not problems uniquely related to AIDS, but occur in many chronic diseases. Once these problems are identified, then a curriculum can be restructured. It is imperative to have a comprehensive, well-integrated curriculum throughout the entire training process. Critical areas that should be stressed are life-style and cultural differences, human sexuality, counseling methods, and preventative medical education, to name a few. A shift from cure to prevention in patient management and patient education is necessary. Changing undergraduate and postgraduate medical training is a slow, tedious process that generally mandates dropping material from an already packed curriculum; however, to accomplish our goal of more meaningful education, this must be done.

Second, if the goal of medical education is the practice of the highest-quality osteopathic medicine, then our educational programs should be modeled after certain practice ideals. Central to this concept is the assurance that a single standard of quality care is maintained despite the development of medical indigence during the course of illness and the presence of patient subgroups who are often recipients of discriminatory behavior by care providers. Like any patient with a chronic progres- sive disease, those who are infected with the HIV or who have AIDS require a broad continuum of care that extends beyond the hospital into the community. Inpatient stays should be intensive, but brief, with the bulk of management provided as outpatient care. A multidisciplinary team approach to patient management, which recognizes the importance of psychosocial and basic living support, will be necessary. This demands the development of broad partnerships between health care providers and support agencies to allow for a greater emphasis on home health care.

Because of the emphasis on providing a large portion of care in the outpatient setting, the primary care physician should remain the principal manager of the person at risk of infection with the HIV. Access to tertiary care facilities is essential to minimize loss of the continuity of care while allowing easy patient access to various communitybased services, which are used routinely by primary care providers.

Additionally, as the incidence of infection and AIDS increases, such patient care positioning probably will meet care demands not likely to be met by tertiary centers alone. Currently, the distribution of resources, chiefly funding, favors patient concentration in tertiary care facilities. Publicly supported referral centers have been the only ones with access to resources for care of the indigent patient. Therefore, the shift of care to communitybased medicine will mean that the primary care system must be recognized as a principal recipient of patient care funding.

In order to create educational and patient care changes, thought must be stimulated and information provided. To that end, the series of articles on AIDS to be presented in the JAOA, beginning with this issue, provide information that should assist us toward our goal-a profession better prepared to deal with AIDS. Professional associations such as the American Osteopathic Association can fulfill the need of providing an excellent vehicle for the timely dissemination of information.

In this issue, Richard Theriault, D.O., provides the necessary background information on the HIV infection and AIDS to assist the reader in developing a general understanding of the disease and its many critical, controversial problems. Subsequent issues will be directed to the psychosocial, psychiatric, legal, and ethical aspects and dilemmas of this disease and the ways in which risks to the patient and health care worker can be reduced. Finally, specific attention will be directed to special problems confronting the primary care physician, including how to recognize persons with high-risk behavior, certain community-related situations 
such as serologic testing, and AIDS in the work place and school.

A vaccine, let alone a cure, is a long way off. Therefore, we must unite as a profession to ensure that our patients are properly educated and cared for. However, before we can meet this obligation, we must educate ourselves. Our patients' lives depend on it.

\author{
GILBERT E. D'ALONZO, D.O. \\ Assistant Professor of Medicine \\ The University of Texas Health Science Center \\ at Houston \\ Chairman, Task Force on AIDS \\ American Osteopathic Association
}

LEONARD CALABRESE, D.O.

Cleveland Clinic Foundation

Member, Task Force on AIDS

American Osteopathic Association
Flaherty, E.M.T.-P., Norwalk paramedic, management of cocaine intoxication involves monitoring the patient's cardiopulmonary status. In their report in the October 1987 issue of American Family Physician, protocol requires administering thiamine combined with 50 percent dextrose and naloxone. Gastric irrigation is performed, followed by charcoal instillation and a bowel evacuating agent. Seizure, a distinct possibility in cocaine intoxication, should be treated intravenously with diazepam.

As law enforcement personnel concentrate more on apprehending drug offenders, the incidence of drug overdose cases due to "body packing" and "body stuffing" will likely increase.

Whole-bowel irrigation is an effective gastrointestinal (GI) decontamination method for use in acute drug overdoses, according to Canadian researchers led by Milton Tenenbein, M.D.

While the efficacy of activated charcoal is greater than that of ipecac-induced vomiting or gastric lavage in decontaminating the GI tract, whole-bowel irrigation can be more effective in reducing drug absorption and increasing toxin excretions than the former methods in certain instances. The researchers advocate whole-bowel irrigation when the patient has ingested large toxic amounts or a delayedreleasing substance; the drug was taken several hours prior to patient presentation; or the abused pharmaceutical, such as iron, cannot be absorbed by charcoal.

The study, reported in the May 1987 issue of $\mathrm{Ar}$ chives of Internal Medicine, involved 9 healthy men, aged 22-27, each of whom ingested $5.0 \mathrm{gm}$. of ampicillin trihydrate capsules with $250 \mathrm{ml}$. of water after 8 hours of fasting. Results showed a 67 percent decrease in ampicillin absorption.

Contraindications in this GI decontamination method include bowel perforation, obstruction, ileus, and GI hemorrhage. In addition, the scientists suggest ipecac syrup should not be administered prior to whole-bowel irrigation as some patients may not tolerate the procedure. 